\title{
XIV. On the potatoe spirit oil of the French chemists
}

\author{
James Apjohn M.D. M.R.I.A.
}

To cite this article: James Apjohn M.D. M.R.I.A. (1840) XIV. On the potatoe spirit oil of the French chemists, Philosophical Magazine Series 3, 17:108, 86-92, DOI: 10.1080/14786444008650121

To link to this article: http://dx.doi.org/10.1080/14786444008650121

曲 Published online: 01 Jun 2009.

Submit your article to this journal $\lceil\pi$

Џ Article views: 3

Q View related articles $\asymp$ 


\section{[ 86 ]}

XIV. On the Potatoe Spirit Oil of the French Chemists. By James Apjohn, M.D., M.R.I.A., Professor of Chemistry in the Royal College of Surgeons, Dublin*.

IN December 1838, I received from my friend Mr. Scanlan a specimen of an oily fluid which had been given him by Mr. Bowerbank, an eminent London rectifier, and which the latter gentleman had found in small quantity in the faints or weak spirit drawn off towards the close of the rectification of common whisky. Shortly previous to this time, Mr. Coffey, the inventor of the celebrated patent still, had observed the same substance at the extensive distillery of Sir Felix Booth; and upon coming over to Dublin, and visiting the establishment of Mr. Busby at Blockpitts in this city, Mr. Scanlan had the satisfaction of recognizing this same oil in the faint vessel, constituting a thin stratum resting upon the surface of the remainder of the fluid.

The oil obtained from Mr. Busby's concern had a reddishbrown colour, owing to dissolved vegetable matter, and its specific gravity was $\mathbf{8 4 0 1}$, that of the faints on which it rested being 9269 . Shaken in a graduated tube with an equal bulk of water, its volume was reduced 20 per cent., and the water upon distillation yielded alcohol. To insulate the oil, therefore, the following method was adopted.

The fluid obtained from the faint receiver was first washed with an equal bulk of water; then shaken in a bottle with an equal weight of pulverized and anhydrous carbonate of potash, and finally distilled from a glass retort, the condensation being effected by Liebig's tube refrigeratory. It began to boil at $262^{\circ}$, after which the temperature rose gradually until it became $268^{\circ}$, at which it continued until the whole of the oil was nearly over. The fluid first drawn off was set apart, as still containing alcohol, and that alone reserved for further purification which distilled over at $268^{\circ}$. This portion was redistilled. The ebullition commenced a little over $267^{\circ}$, and in less than a minute rose to $268^{\circ}$, at which point it continued until the rectification was nearly completed. The first and last portions being rejected, the middle portion, or that which came over at $268^{\circ}$, was set apart for experiment.

The oil thus procured is a perfectly colourless liquid, destitute of all viscidity. The specific gravity is 8138 , and, as has been already observed, it boils steadily at $268^{\circ}$; cooled to $-6^{\circ}$ it does not congeal. With rectified spirit it is miscible in all proportions, its specific gravity being thus ang-

- Communicated by the Author. 
mented, and its boiling point lowered. It is immiscible with water, but nevertheless when agitated with this liquid, it absorbs an appreciable quantity of it. It has a pungent and peculiar odour, and a sharp biting taste, somewhat similar to that of the oil of cloves. When gently heated it readily takes fire upon approaching to it a lighted taper, and burns with a clear flame unaccompanied by smoke. It is an excellent solvent for the fats, and also for resinous substances. Camphor, for example, is readily dissolved by it; and the same may be said even of copal, if a gentle heat be applied. Potash is taken up by it in considerable quantity, oil of vitriol gives it a crimson colour. To determine its composition the following experiments were made:

(1.) 4.24 grains of the oil burned in the usual manner with oxide of copper gave of water 5.06 grains, and of carbonic acid 10.42 grains.

(2.) 7.71 grains gave of water $\mathbf{9 . 2 2}$ grains, and of carbonic acid $19 \cdot 12$ grains.

(3.) 6.63 grains gave of water 8.05 grains, and of carbonic acid $16 \cdot 26$ grains.

The following are the results deducible from these experiments :

(1.)

Carbon......... 67.96

Hydrogen .... 13.25

Oxygen ........ 18.79

100
(2).

$68 \cdot 59$

$13 \cdot 28$

$18 \cdot 13$
(3.)

$67 \cdot 84$

$13 \cdot 4.8$

$18 \cdot 68$

The means of the numbers yielded by the three experiments are given underneath in column $(a$.$) . The numbers in$ column $(b$.$) are the quotients of the corresponding ones in$ (a.) divided by the respective atomic weights of carbon, hydrogen, and oxygen, and those in column $\left(c_{0}\right)$ are others in the same ratio with the quotients.

$\begin{array}{cccc} & (a .) & (b .) & (c .) \\ \text { Carbon ....... } & 68 \cdot 13 & 11 \cdot 132 & 4 \cdot 004 \\ \text { Hydrogen ... } & 13.33 & 13.330 & 5 \cdot 753 \\ \text { Oxygen ....... } & 18 \cdot 54 & 2 \cdot 317 & 1.00\end{array}$

The inspection of the latter shows that the most probable formula for the oil is $\mathrm{C}_{5} \mathrm{H}_{6} \mathrm{O}_{1}$, which would give the following parts per cent.

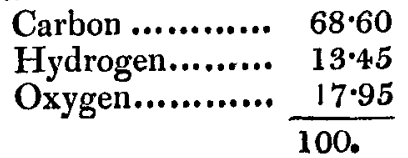


Assuming this formula as the true one, the deficiency in the carbon experimentally determined is not greater than what usually takes place; but the error in the hydrogen, though trifling in amount, being upon the opposite side to that on which it usually occurs, it became expedient to resort to some method of verification. 'The specific gravity of the vapour of the oil was therefore taken according to the wellknown method of Dumas.

The weight of glass ball filled with dry air, the pressure being 30.324 and temperature $48^{\circ} \cdot 5$, was $914 \cdot 86$ grs.

The ball was sealed at $364^{\circ}$, and then weighed $917.78 \mathrm{grs}$. Hence $917.78-914.86=2.92$ grains is the excess of the weight of vapour in ball over that of the air displaced.

The capillary end of the beak attached to the ball having been broken under mercury, it was ascertained by the amount of this metal which flowed into the ball, that its capacity was 16.76 cubic inches, which, at a pressure $=30$, and a temperature $=60^{\circ}$, will (supposing it air) become $16^{\circ} 76$ $\times \frac{448+60}{4.8+48.5} \times \frac{30.324}{30}=17.333$ cubic inches. From this must be subtracted $\cdot 1$ cubic inch which was found to remain in the balloon, so that the bulk of air excluded by the vapour, when reduced to the mean temperature and pressure, was $17 \cdot 233$ cubic inches, whose weight $=5 \cdot 344$ grains. Hence $2.92+5.344=10.264$ is in grains the weight of the vapour.

The capacity of the glass balloon at $48^{\circ} .5$ being 16.76 cubic inches, it will, owing to the expansion of glass, become at $364^{\circ}$ 16.843 inches. This therefore is the volume of the vapour and bubble of air at $364^{\circ}$. But the volume of the latter being $0 \cdot 1$, it will at $364^{\circ}$ become $0 \cdot 16$. Hence the true volume of the vapour at $364^{\circ}=16.84 .3-0.16=16.683$; so that $16.683 \times \frac{448+60}{448+364} \times \frac{30.324}{30}=10.549$ is the volume of the vapour reduced to a temperature $=60^{\circ}$ and pressure $=30$. But as this weighs 10.264 grains, 100 cubic inches of it would weigh 97.298 grains. The specific gravity therefore of the vapour is $\frac{97 \cdot 298}{31 \cdot 0117}=3.137$.

Now if the composition of the oil be $\mathrm{C}_{5} \mathrm{H}_{6} \mathrm{O}_{1}$, the specific gravity got by adding together the products of the densities of the vapours of the different elements by the number of atoms of each would be $3 \cdot 072$. But we have here so close a correspondence between experiment and calculation, that no doubt can remain as to the correctness of the basis on which 
the latter rests, or that the true formula for the oil is that already assigned.

These experiments were made in the winter of 1839 , and at the time $I$ had concluded them $I$ was under the impression that the oil, to which they relate, was a new substance, or rather one which had not been previously described. In some time after, however, upon looking over the second part of Mr. Graham's Elements of Chemistry, which had been sent me by the author, I was much surprised at finding at page 134 , in a table of the volumes of atoms in the gaseous state, mention made of a substance under the designation of " oil of the ardent spirit from potatoes," to which he attributed the very same formula and density of vapour which $I$ had found to belong to the oil found in grain-whisky, in the examination of which $I$ had been recently engaged.

Anxious to investigate the matter further, and to ascertain if the two oils were certainly the same, I looked into Berzelius's System, and the 5th volume of the Traité de Chimie, appliquée aux Arts, by Dumas, devoted to the subject of organic chemistry, but could not find any mention in either of the essential oil from potatoe spirit alluded to by Graham. Upon, however, turning to Dr. Thomson's recent volume on vegetable chemistry, I found, page 481 , a notice of this fluid, and references to the 30th and 56th volumes of the Annales de Chim. et de Phys. in the former of which its origin and properties are described by Pelletier, and in the latter of which its analysis is detailed by M. Dumas. The properties I find ascribed by these chemists to the potatoe spirit oil are precisely those which belong to that which I have examined from corn-whisky, the only difference being that Pelletier represents its specific gravity as $\cdot 821$, whereas I have found that of the oil I obtained from $\mathrm{Mr}$. Scanlan but 813 , a difference, however, easily explained by the circumstance of his not having taken the necessary steps for rendering the fluid he examined perfectly free from water and alcohol. The analytic results also of M. Dumas are nearly identical with mine, approaching however more nearly, as might indeed be expected from his great skill in this department of chemistry, to the formula $\mathrm{C}_{5} \mathrm{H}_{6} \mathrm{O}_{1}$ which he adopts, and which Professor Graham has taken from his memoir. I may lastly mention, as a very unusual coincidence, that the specific gravity of its vapour, as obtained by Dumas, is $3 \cdot 147$, or but unity in the second place of decimals greater than what has resulted for the corn-spirit oil from my experiments.

We thus arrive at the conclusion, that the two fluids are identical, or that the oil which has hitherto been considered 
as peculiar to potatoe spirit, occurs also in that which is developed during the fermentation of grain. From this latter source it admits of being procured in great quantity. When first observed by Mr. Coffey at Sir Felix Booth's, there was an inch of it in the faint receiver, and from the diameter of the vessel he estimated its total amount at 50 gallons. This is the quantity produced at that establishment every fortnight, the excise laws compelling the distiller to distil and brew alternately, and a week being generally consumed in each process.

The whisky manufactured some years ago contained a considerable quantity of this oil, and owed to its presence a great deal of the pungency of taste by which it was distinguished.

From its high boiling point, and the nature of the stills at present used, but a very small portion of this substance now passes over, and hence the reason why the spirit at present made is, as compared with the product of the old processes, less disagreeable to the palate, and probably less injurious to the constitution. It is no doubt owing to the same cause, viz. an improvement in the process of distillation, that this oil has at length been noticed in the distillers' faints. Upon the old system of manufacture the greater portion of it was driven over, and was held dissolved by the spirit into which it was thus introduced; but with the modern stills, particularly that devised by $\mathrm{Mr}$. Coffey, nothing having so high a boiling point as this oil can by possibility pass into the part of the apparatus where the spirit is condensed. With respect to the manner in which the substance originates, whether it exists ready-formed in the materials subjected to fermentation, or is a product of the process, I am not aware of any facts calculated to decide such a question. As, however, it is found in the fermented wash of both corn and potatoes, it may be presumed to be derived from the starchy principle, which is common to both.

The potatoe spirit oil, as it has hitherto been called, has I find of late attracted much attention. Pelletier from some rough experiments upon it with acids, threw out the conjecture that it was more analogous to alcohol than to the true volatile oils, and this opinion would seem to have been in some degree adopted by Dumas. More recently (Ann. de Chimie et de Phys., Jan., 1839) M. Auguste Cahours has revived this opinion, and concluded it to be one of the group including alcohol, pyroxylic spirit, and acetone, and has even succeeded in procuring from it a carbo-hydrogen, in which the elements are, as usual, associated in the ratio of atom and atom. M. 
Cahours represents potatoe oil by the formula $\mathrm{C}_{10} \mathrm{H}_{11} \mathrm{O}_{1}$ $+\mathrm{H} \mathrm{O}$, which makes it as to composition perfectly analogous to ordinary alcohol. The carbo-hydrogen $\mathrm{C}_{10} \mathrm{H}_{10}$ he insulated by distilling the oil from anhydrous phosphoric acid. He calls it amylene, and finds the specific gravity of its vapour to be 4.904 , so that an atom of it gives but one volume of vapour, a circumstance in which, as Cahours observes, it agrees with Dr. Kane's mesitylene, $\mathrm{C}_{6} \mathrm{H}_{3}$, but differs from the carbohydrogens which occur in alcohol and pyroxylic spirit. By acting on potatoe oil with sulphuric acid and chlorine, $\mathrm{Ca}$ hours obtained compounds corresponding perfectly with those yielded by alcohol when similarly treated. These researches give additional interest to the discovery of this fluid in grainfermented wash, and in such quantity as to be much more than adequate to meet any demand for it with a view to the interests of science.

I may here observe, that I should have long since presented this notice to the Academy, but for the following reasons.

There is another oily substance having, at common temperatures, the consistence of butter, which is long known to exist in the faints of grain spirit, and in smaller quantity in the spirit itself. Upon looking through systematic treatises on chemistry, I found that this oil had been but very imperfectly described, and that, in particular, no experiments had been made with the view of determining its composition. I had therefore resolved to submit it to an accurate examination and analysis, and to keep back what $I$ had ascertained in reference to the fluid oil until I had completed my investigations into the nature and constitution of that which is a soft solid at common temperatures. In this investigation I had made some progress, when my attention was directed to a paper by Liebig and Pelouze, in the 63rd volume of the Ann. de Chim. et de Phys., in which, with their usual ability, they develope the nature of a butyraceous or fatty product which they had received from M. Deleschamps, and which comes over towards the close of the process of distilling wines with a view to the production of eau de vie or brandy. This oil they found to be a mixture of an acid which they called onanthic acid, and of a compound of this acid with the oxide of athyle, that is of cnanthic acid and œnanthic æther. Upon perusing this paper I saw at once, from the experiments I had already made, that the fatty oil of grain spirit was identical with this mixture, with the exception that some third oleaginous material was present, which Liebig and Pelouze had not found in what they had operated upon. Upon this third substance $I$ have made some experiments, the results of which I shall probably at some 
future period submit to the Academy. I have resolved, however, no longer to defer giving publicity to my experiments identifying the fluid oils of grain and potatoe spirit, having had my attention drawn by Dr. Kane to a recent volume of Poggendorff's Annalen, containing a paper by M. Mulder, in which I find myself anticipated on the other point; and the butter of corn spirit is satisfactorily shown to be what $I$ had concluded it to be, not entirely from my own experiments, but from a comparison of them with the researches of Pelouze and Liebig. Mulder also notices the third principle which is associated with the œnanthic acid and onanthic æther, and describes it under the name of oleum siticum. The object therefore of the present communication is much more limited than it was originally intended to be, professing only to announce the detection of the potatoe-spirit oil of Pelletier and Dumas in fermented infusions of the mixed grains employed by the distiller. But as Mulder conceived his discovery of sufficient interest to justify him in giving it to the scientific world, I shall, I trust, be pardoned for bringing an analogous fact under the notice of the Academy.

XV. Observations on the Climate of Italy and other Countries in ancient times*.

A VAGUE notion seems to have prevailed for some time A past among persons conversant with ancient authors, that the climate of Europe in the classical ages of Greece and Rome must have been considerably colder than at the present day. Latterly this question has been taken up by two philosophers, who from a consideration of the vegetation have come to a different conclusion. Most persons probably have read the interesting essay by Arago in the Annuaire for 1834, who states that several of his facts have been borrowed from the writings of Schouw. The conclusions drawn by these writers are probably in the main correct; but some of the facts stated by them appear to require modifications, which are more fully explained in the following pages.

\section{Vegetation of Ancient Italy: the beech, the date-palm, the olive.}

It has been said that Virgil speaks of the beech as growing in the neighbourhood of Rome; whereas now the climate is too hot for that tree, which is not found till we reach a considerable height on the Apennines. In fact, Tenore (Cenno

* Communicaled by the Author. 